\title{
ALTERNATIVE THERAPIES FOR THE HOLISTIC CARE OF THE HIV/AIDS PATIENT
}

\section{Candice Bodkin}

BSc (Genetics), BNurs, MSc

Lecturer, Department of Nursing Education, University of the Witwatersrand

Correspondence: harrisc@therapy.wits.ac.za

Keywords: HIV/AIDS; holistic nursing care; alternative therapies

\begin{abstract}
The holistic nursing care of individuals infected with HIV/AIDS involves promoting psychological and physiological well-being as well as fostering socio-cultural relationships and supporting the fulfilment of spiritual aspirations. HIVIAIDS is a complex disease requiring complex holistic nursing care. The allopathic management of HIVIAIDS takes a biomedical approach and includes treatment with highly active antiretroviral therapy (HAART). HAART is not entirely beneficial on it own. Alternative therapies can be used as an adjunct to HAART. Alternative therapies provide a means of providing holistic nursing care to HIVIAIDS infected individuals and thus ensuring overall wellbeing of the HIVIAIDS infected individual. Alternative therapies that can be used for the holistic nursing care of HIV/AIDS infection include psychological, mental and emotional therapies, therapeutic touch, nutrition, vitamins, minerals and nutritional supplements, herbal medicine, Chinese medicine and homeopathy, traditional medicine, lifestyle changes and fostering spiritual well-being. This article provides an overview of alternative therapies that can be used in the holistic nursing care of the HIVIAIDS patient.
\end{abstract}

\section{OPSOMMING}

Die holistiese verpleegsorg van individue met HIVIVIGS behels die bevordering van psigologiese en fisiologiese welsyn, sowel as die bevordering van sosio-kulturele verhoudings ten einde geestelike strewes te verwesenlik. HIVIVIGS is 'n komplekse siektetoestand wat komplekse holistiese verpleegsorg vereis. Die alopatiese behandeling van HIVIVIGS impliseer die gebruik van 'n biomediese benadering sowel as die toediening van hoogs aktiewe antiretrovirale terapie (HAART). HAART in isolasie toegedien, is nie volkome voordelig nie. Alternatiewe terapieë kan saam met HAART benut word. Die gebruik van alternatiewe terapieë stel verpleegkundiges in staat om holistiese verpleegsorg vir die HIVIVIGS-pasiënt aan te bied, aangesien dit tot die algehele welsyn van die HIV/ VIGS pasiënt bydra. Alternatiewe terapieë wat gebruik kan word in die holistiese verpleegsorg van die HIVIVIGSpasiënt sluit in psigologiese terapie, terapeutiese aanraking,voeding, vitamiene, minerale-en voedingsaanvullings, kruiemedikasie, Chinese medikasie, homeopatie, tradisionele medisyne, lewenstylverandering en geestelike welsyn. Hierdie artikel verskaf 'n oorsig van die alternatiewe terapieë wat benut kan word in die holistiese verpleegsorg van die HIVIVIGS-pasiënt. 


\section{INTRODUCTION}

In the last two decades HIV/AIDS has entered the consciousness of South Africans and those worldwide as an incomprehensible calamity. It has taken a terrible toll, claiming human lives, inflicting pain and grief, causing fear and uncertainty and threatening physical, psychological, social and spiritual well-being of the HIV/ AIDS infected individual. The HIV/AIDS calamity is exacerbated by the fact that no cure is available and as a result, as many as 40 million people worldwide are expected to be infected with HIV/AIDS. It is recommended within the HIV/AIDS/STI Strategic Plan for South Africa, 2000-2005 (Department of Health (DOH), 2000), that a holistic approach should be taken when treating HIV/AIDS infected individuals as well as collaboration with traditional healers and alternative practitioners, to improve the health and well-being of HIV/AIDS infected individuals (DOH, 2000).

In order to provide effective holistic nursing care to HIV/AIDS infected individuals it is necessary to have an understanding of health, holistic health, well-being and alternative medicine. The World Health Organisation (WHO) defines health as, "the state of complete mental, physical and social well-being and not merely the absence of disease or infirmity". This definition maintains concern for the individual as a complete being and includes the importance of the individual's role in creating his/her health. The holistic management of HIV/AIDS is in line with the WHO definition of health as it not only encourages selfresponsibility for health but also allows a holistic view of the individual (Ress, 2001:75).

The Canadian Holistic Medical Association defines holistic health as, "a system of health care which fosters a co-operative relationship among all those involved, leading towards optimal attainment of physical, psychological, social and spiritual well-being". The provision of holistic health care is integral to the philosophy of nursing and thus holistic nursing care is not a new concept, however the provision of holistic nursing care by means of alternative therapies to ensure the well-being of HIV/AIDS infected individuals is a relatively new concept. Holistic nursing care involves promoting well-being on all levels. Well-being "is an integrated method of functioning orientated toward maximising the potential of which the individual is capable. It occurs when physical, psychosocial and spiritual needs are met in ways that support maximum functioning" (Ress, 2001:75).

HIV/AIDS is a complex disease that requires complex holistic nursing care. Alternative medicine is a system of holistic health that could provide for the holistic needs of the HIV/AIDS patient. Alternative medicine is defined as "the scientific and non-scientific interventions that diverge from allopathic or western medicine for the treatment of HIV/AIDS. It is those practices explicitly used for the purpose of medical intervention, health promotion and disease prevention which are not routinely taught at health science faculties nor routinely underwritten by third party payers within the health care system" (De Visser \& Grierson, 2002:599). Alternative medicine involves the noninvasive and non-pharmaceutical management of HIV/ AIDS. Conversely, the allopathic treatment of HIV/AIDS involves invasive and pharmacological methods.

The allopathic management of HIV/AIDS is based on a biomedical framework and involves combination therapy with antiretrovirals (ART). Most commonly used ART include Zidovudine (AZT or ZDV), Lamivudine (3TC) and Nevirapine (NVP). These are combined as triple therapy or highly active antiretroviral therapy (HAART). For those who have access to HAART, they need to rely on perfect adherence to the multi-drug regimen for years in order for it to be effective. However, the question posed is: Why should alternative therapies be considered when HAART holds all the answers, or does it? Alterative therapies for the management of HIV/AIDS are necessary for the following reasons: Research on HAART that is safe for use on children is limited. The HIV virus is highly adaptable and its ability to mutate is its key to evading attack by antiretrovirals. HAART has many benefits, but it is the harm of side effects that they cause, that necessitates the need for research into other methods of HIV/AIDS management. HAART is offered to HIV/ AIDS patients who have a CD4 count below 350 or are symptomatic (Bartlett \& Gallant, 2000). What about the rest of the HIV positive population? Antiretrovirals reduce viral load initially but do not offer a cure for HIV/AIDS infection and virtually all studies show a viral rebound within 12 weeks of discontinuing HAART (Bartlett \& Gallant, 2000). Nevirapine has been found in many studies to reduce viral transmission from 
mother to foetus, although effective these drugs are not always available. The process of finding a treatment and distributing the treatment to HIV infected individuals has been timeous thus resulting in reduced trust in the medical fraternity. Other problems faced by HIV/AIDS infected individuals with respect to HAART are expense and HAART has reduced sustainability and reduced durability of benefits. HAART has long-term side-effects, including lipodystrophy, reduced lifespan, altered lipid metabolism and insulin resistance (Ress, 2001:72).

HAART is also not entirely beneficial on it own. Literature extrapolates the benefits of stress reduction, social support, nutritional supplementation and behaviour change; thus self-care of HIV positive individuals reduces HIV related complications. HIV is multifaceted and complex and thus requires multifaceted and complex intervention. Alternative therapies are useful when used to complement HAART, as it improves energy levels, reduces the sideeffects of HAART and other prescribed medicines and thus contributes to overall well-being.

HIV/AIDS infected individuals can select from a very broad range of alternative therapies. These include psychological, mental and emotional therapies, therapeutic touch, nutrition, vitamins, minerals and nutritional supplements, herbal medicine, Chinese medicine and homoeopathy, traditional medicine, lifestyle changes and spiritual well-being (De Visser \& Grierson, 2002:599-606).

Alternative therapies have many advantages for use in the treatment of HIV/AIDS. Firstly, alternative therapies allow holistic nursing care. Secondly, alternative therapies may be useful in the treatment of HIV/AIDS infected children as they have few side effects; they are useful in the prevention of opportunistic infections; alternative therapies improve immune functioning and they are cheaper than HAART. Finally, research has demonstrated that HIV/AIDS infected individuals selecting alternative therapies maintain the belief that the therapies are safe but not curative. They believe that alternative therapies will strengthen their body's immune system and will delay the progression of the disease. However, further research on safety is still required (Elion \& Cohen, 1997:907-908; Wilson, Naidoo, Bekker, Cotton \&
Maartens, 2002:430).

HIV/AIDS infected individuals are faced with many problems. These can be classified as psychological, physical, social and spiritual problems. Standish, Greene, Bain, Reeves, Sanders, Wines, Turret, Kim and Calabrese, (2001:197) mention HIV/AIDS related problems that may respond to alternative therapies. Mental and emotional problems include memory loss, problems with concentration, depression and persistent fatigue. The physical conditions include skin rashes, diarrhoea, low grade and persistent fevers, lymphadenopathy, persistent headaches, aches and pains and night sweats. Alternative therapies are useful in the treatment of infections, such as oral candidiasis, and for the prevention and treatment of mild respiratory tract infections, gastro-intestinal infections and urinary tract infections. Alternative therapies can be used to improve the nutritional status of the HIV/AIDS infected individual. Alternative therapies can be used to aid the management of social problems such as prejudice, community apathy, stigmatisation, rejection and lack of community and political support. The spiritual problems include coping with the perception that HIV is terminal and untreatable and death and dying.

\section{HOLISTIC NURSING CARE AND WELL- BEING}

Well-being of the HIV/AIDS infected individual can be achieved through providing holistic nursing care. The psycho-neurological-immunological response provides a way of looking at the usefulness of holistic nursing care and alternative therapies in ensuring the wellbeing of HIV/AIDS infected individuals. The psychoneurological-immunological response is an immunological response significant in HIV/AIDS infected individuals. The psycho-neurologicalimmunological response occurs due to direct neuronal access from the central nervous system to organs of the immune system, thus psychosocial stress, such as stigmatisation, lack of social support, anxiety and depression experienced by HIV/AIDS infected individuals results in suppression of the immune system and thus susceptibility to opportunistic infections. This mind-body communication not only involves the immune system but can also involve the autonomic nervous system and the endocrine system. Thus psychosocial stress can also result in muscle 
tension, tremor, and sweating and hormonal imbalances. The psycho-neurological-immunological response acts in a bio-directional manner. Thus biophysical stress, such as an opportunistic infection due to immunosupression, can trigger psychosocial responses such as insomnia and social withdrawal, often observed in HIV/AIDS infected individuals. In order to ensure overall well-being, psychological, physical, social and spiritual well-being is vital (Ress, 2001:75).

The nurse's role in ensuring the well-being of the HIV/ AIDS infected individual through the use of alternative therapies is described as follows: Alternative therapies do have side-effects and drug interactions, for this reason a thorough history of a patient's alternative therapy use is required. In addition the nurse is required to keep abreast with the latest HIV and alternative therapy developments, so as to ensure that the patient receives accurate and unbiased information. All patients should receive voluntary and confidential HIV counselling. In order to achieve sustainability there should be sufficient resources to pay for the long-term, reliable and regular supply of alternative therapies and this health care provision should be affordable. These resources should be utilised efficiently by keeping expensive care to a minimum by referring early to a system that is appropriate. Also, staff requires diagnostic abilities so as to diagnose complications and opportunistic infections early and to refer the patients for the appropriate treatment. HIV/AIDS infected individuals are the leaders in health care provision and their decisions should be accepted in a non-judgemental manner. As a result an empowered patient will embark on a sustainable health care program. Alternative health care provision requires a program of quality control and ethical and legal consideration and administration issues need to be taken into consideration. Policies are required on guidelines for good clinical management, guidelines for prescription of alternative therapies and good counselling. Finally, multidisciplinary and multisectorial collaboration are required for holistic nursing care.

Alternative therapies can be applied to nursing practice in any setting, ranging from home-based care to community clinics, hospital-based care, critical care and palliative care. Alternative therapies can be included in routing daily nursing care, during routine clinic visits, during patient education and in assisting a terminal patient.

Holistic nursing care can apply alternative therapies for the management of HIV/AIDS in the following manner.

\section{PSYCHOLOGICAL WELL-BEING}

Alternative therapies address the psychological wellbeing of the HIV/AIDS infected individual by providing psychological, emotional and mental well-being and through therapeutic touch.

\section{Psychological, emotional and mental well- being}

It is a well-known fact that psychological, mental and emotional well-being is vital for an optimum state of physical health (Ress, 2001:75), this is especially true for individuals with HIV/AIDS. Alternative medicine has many therapies to address psychological, emotional and mental well-being. These therapies are a therapeutic milieu, herbal remedies, meditation and visualisation, supportive counselling, energetic healing, intuitive healing, colour therapy, psychotherapy, breathing exercise, spiritual activities, homoeopathy and Chinese medicine and psycho-neuro-immunology (Greene, Berger, Reeves, Moffat, Standish \& Calabrese, 1999:60; Wardell \& Engebretson, 2001:445). A psycho-neurological-immunological response can be stimulated through therapeutic touch.

\section{Therapeutic touch}

Therapeutic touch can be offered to the HIV/AIDS infected individual in various forms. These include therapeutic massage, reflexology, aromatherapy and Reiki. Therapeutic touch has gained popularity in HIV/ AIDS management due to its many palliative affects. Therapeutic touch results in a mutual exchange of energy between the nurse and the patient. It is the systemic manipulation of the soft tissues of the body to restore metabolic and energetic balance to the body. Patients state that they feel calmed soothed and more energetic following therapeutic touch, thus making them more able to cope with other symptoms of HIV/ AIDS (Elion \& Cohen, 1997:914-915; Wardell \& Engebretson, 2001:45). 
Aromatherapy, a form of therapeutic touch, involves the application of essences to the skin during massage and these can act as antimicrobials and antioxidants and have other pharmacological actions on the cells. Studies have shown that essential oils have an effect on brainwaves and can alter behaviour. It is possible that the effect of the oil is transmitted from the olfactory system to the brain. Used professionally and safely, aromatherapy can have great benefits as an adjunct to allopathic medicine or used simply on its own (Ress, 2001:75).

Massage is one of the most important actions performed in aromatherapy. Massage alone has benefits for the HIV/AIDS infected individual. Massage is said to assist in pain control through cutaneous stimulation. Two explanations have been proposed regarding the efficacy of cutaneous stimulation. Firstly, it stimulates nerve fibres and thus encourages the release of endorphins, which have analgesic properties. Secondly, cutaneous stimulation produces relaxation, which reduces anxiety and which in turn reduces pain threshold (Hulme, Waterman \& Hilloer, 1999:460-468; Wardell \& Engebretson, 2001:445).

Therapeutic touch not only has psychological benefits but also has physiological benefits. A discussion on the alternative therapies that evoke physiological wellbeing follows.

\section{PHYSIOLOGICAL WELL-BEING}

The physiological well-being of the HIV/AIDS infected individuals is addressed through the provision of nutrition, vitamins, minerals and nutritional supplements, herbal medicine, Chinese medicine and homoeopathy.

\section{Nutrition}

There is an interrelationship between malnutrition and poor prognosis in HIV/AIDS infection. HIV/AIDS infection results in malnutrition and in turn malnutrition results in an increased susceptibility to opportunistic infections, which cause diarrhoea, malabsorption, fever and loss of appetite. The result is reduced energy intake and thus a downward cycle towards a poor prognosis (Wilson et al. 2002:415).
Individuals with HIV/AIDS infection are found to be deficient in several micronutrients. The most common deficiencies are vitamin B12 and vitamin B6 deficiencies, which result in mouth sores, glossitis, cheilosis, weakness, mental status changes, loss of appetite and reduced food intake. Fat malabsorption results in a deficiency of fat-soluble vitamins, which include vitamins $A, D, E$ and $K$. Minerals such as zinc and selenium have also been found to be deficient (Elion \& Cohen, 1997:909-911; Wilson et al. 2002:430).

In order to maintain the nutritional status of the HIV/ AIDS infected individual certain goals need to be applied. The first goal is to preserve the nutritional status of the patient. This can be achieved through the increased intake of nutritious food and through increasing the patient's appetite. Included in the diet, the HIV/ AIDS infected individual requires body building foods, energy foods and protective foods. The second goal would be to prevent micronutrient and macronutrient deficiencies, which result in a poor immune system. The third goal would be to reduce the complications that interfere with nutrient intake and absorption. The final goal is to improve quality of life by preventing malnutrition (Elion \& Cohen, 1997:909-911; Wilson et al. 2002:430).

\section{Nutritional considerations for the HIV/ AIDS infected individual}

The nutritional needs of the HIV/AIDS infected individual are of utmost concern as the nutritional needs are greater than normally expected. Malabsorption, muscle wasting and opportunistic infections compound the nutrition problem in HIV/AIDS infected individuals (Elion \& Cohen, 1997, 909-911; Balch \& Balch, 1997:100-101; Wilson et al. 2002:415).

- The diet should consist of $75 \%$ raw fruit and raw or lightly cooked vegetables. These have a high nutritional value and vitamins and enzymes have not been denatured. Juiced fruit and vegetables are highly beneficial.

- Cruciferous vegetables should be consumed daily. These include, broccoli, Brussels sprouts, cabbage and cauliflower.

- At least 1.5 litres of clean water should be consumed daily as water flushes out toxins and hydrates vital organs.

- Encourage the consumption of homegrown onions and garlic daily as these stimulate immune 
function.

- Elimination of coffee, diet drinks, foods with additives and colouring, 'fast foods', processed and refined foods, saturated fats, salt, sugar and sugar-containing foods and white flour or refined carbohydrates should be encouraged.

- Increase consumption of fibre, either take psyllium husks daily or a bran cereal.

- Exercise caution in selection of food so as to avoid food-borne infections.

- Also exercise caution in personal hygiene whilst preparing food and ensure safe preservation of food.

- Encourage reduced consumption of alcohol and cigarette smoking,

These nutritional considerations are required in order to prevent nutritional deficiencies. Where it is not possible to apply nutritional considerations, vitamins, minerals and nutritional supplements are required.

\section{Vitamins, minerals and nutritional supplements}

Vitamins, minerals and other supplements are an important aspect of alternative management of HIV/ AIDS infection. These are classified according to the role that they perform in the management of HIV/AIDS. Classification is as follows: antioxidants, antiinflammatory agents, immunomodulatory agents and nutritional supplements.

\section{Antioxidants}

Oxidation is the creation of an abnormal biochemical environment at cellular level. Oxidation at a cellular level is dangerous as it makes the body more susceptible to cellular injury and even cancer. Oxidative stress can be prevented through the introduction of antioxidants. Such substances include beta-carotene, selenium, Pycnogenol, vitamin E, vitamin $\mathrm{C}$ and Coenzyme Q10.

Beta-carotene and vitamin A are important in immune function. It has been postulated that an individual suffering from a chronic viral infection may benefit from vitamin A. The water-soluble form of vitamin $A$ is called beta-carotene and is a well-known antioxidant. Clinical trails have demonstrated a rise in CD4 count after the daily administration of $180 \mathrm{mg}$ of beta-carotene.
Beta-carotene has however not been found beneficial unless a deficiency is present (Heinrich, Gärtner, Wiebusch, Eichler, Sies, Tronnier \& Stahl, 2003:98).

Selenium is an antioxidant and an essential mineral. The effects of selenium are dose-related. The mineral is given in doses lower than 200mg daily so as to avoid toxicity. There appears to be a relationship between selenium deficiency and poor immune function. Selenium deficiency commonly manifests in abnormal CD4 cell function and candidiasis. Selenium is also found to be deficient in patients with malabsorption disorders. Thus there is a correlation between selenium deficiency and HIV/AIDS disease progression (Wilson et al. 2002:415).

Pycnogenol or grape seed extract and vitamin E are potent antioxidants. It has been postulated that the vitamin $E$ forms the membrane-based element of antioxidant defence (Wilson et al. 2002: 415).

Vitamin $C$ is another antioxidant useful in HIV/AIDS management. Increased consumption of vitamin $C$ in HIV positive individuals results in slower disease progression (Piscitelli, 2000). Vitamin $C$ acts by protecting cells from oxidative damage. These cells include cells of the immune system. Studies have demonstrated that vitamin $\mathrm{C}$ has the ability to raise intracellular glutathione and $\mathrm{N}$-acetyl cysteine (NAC) and directly inhibits viral replication. In the light of the body's inability to manufacture vitamin $\mathrm{C}$, it has to be obtained through the diet or through supplementation. For maximum effectiveness vitamin $\mathrm{C}$ should be taken in divided doses twice daily. The use of high doses of vitamin C (1-6 g/day) for the prevention and treatment of the upper respiratory tract infections is recommended. Esterfied vitamin $C$ is the most effective form of vitamin C (Douglas, Chalker \& Treacy, 2000).

Co-enzyme Q10 is a vitamin-like substance whose actions in the body resemble vitamin $\mathrm{E}$. It also has the function of an antioxidant. This substance plays a critical role in the production of energy in every cell in the body. It aids circulation, stimulates the immune function and increases tissue oxygenation. Oily fish have been found to be rich in Co-enzyme Q10, which includes salmon and sardines, and it is also found in beef, peanuts and spinach (Piscitelli, 2000). 


\section{Anti-inflammatory agents}

$\mathrm{N}$-Acetyl cysteine (NAC) is thought to cause a reduction of inflammatory symptoms in arthritis and other diseases. This substance has been found to be low in HIV positive individuals. By increasing NAC levels in HIV positive individuals one can reduce inflammation and increase life expectancy (Elion \& Cohen, 1997:911).

\section{Immunomodulatory agents}

Immunomodulatory agents include zinc and glutamine. Zinc may have many benefits for the management of HIV/AIDS as zinc can be described as an optimal nutrient for immune function. The success of sucking zinc lozenges can be attributed to zinc ions that inhibit replication of various viruses. Low dosages of zinc stimulate the immune system, but high doses of zinc may be immunosupressive (Kirkpatrick, 1996:671; Wilson et al. 2002:430). Zinc is useful in preventing respiratory tract infection, which occurs frequently in immunocompromised individuals. The dose to prevent respiratory tract infections is 15 to $25 \mathrm{mg}$ daily (Wilson et al. 2002:415).

Glutamine is a supplement that has received attention because of its potential benefit for HIV/AIDS positive patients. Symptomatic HIV/AIDS infected individuals have higher metabolic needs and thus glutamine demand may be increased. A glutamine deficiency results in muscle loss and decreased immune function. Phagocytic function is also thought to increase with the intake of glutamine. In addition, colonic tissue is known to utilise glutamine in higher rates in HIV/AIDS infected individuals, possibly relating to delayed colonic mucosal repair and potential malabsorption. Administration of glutamine in postoperative intensive care patients has shown to improve absorption of nutrients and encourage a more rapid recovery (Elion \& Cohen, 1997:911).

\section{Nutritional supplementation}

Nutritional supplements include vitamin B6 and B12, propolis, spirulina, barley juice and kelp, acidophilus, protein powders and colloidal silver (Balch \& Balch, 1997:100-101; Wilson et al. 2002:430).

The B vitamins play an important role in HIV management. Niacin and vitamin B6 normalise immune function and lead to greater immune responsiveness. Vitamin B12 is important for neural and cognitive function. Vitamin B12 may prevent or improve neuropathy. The vitamin B complex also aids the patient to cope better with stress and depression.

Propolis is a resinous substance that is collected from plants by bees. Bees use the propolis together with beeswax to construct their hives. As a supplement it is an excellent agent against viral and bacterial infections. Propolis stimulates phagocytosis and is thus useful for the prevention of respiratory tract infections and opportunistic infections, as it enhances the immune system and it reduces inflammation of the mucous membranes. Propolis is beneficial as a tonic to enhance the immune system, as it is rich in vitamins, minerals and trace elements.

Spirulina is a micro-algae, which is rich in protein and is an immediate food source. Spirulina thrives in sunny, hot climates and in alkaline water. Spirulina contains the following nutrients, gamma-linolenic acid, linoleic and arachidonic acids, vitamin B 12, protein, iron, amino acids, nucleic acids and chlorophyll. Spirulina is naturally digestible and aids in protecting the immune system.

The combination of barley juice and kelp is a rich source of calcium, iron, essential amino acids, chlorophyll, flavonoids, vitamin B12, vitamin C and many other minerals and enzymes. It is also an effective anti-inflammatory agent .

Acidophilus, an essential 'friendly' bacterium, is vital for digestive function, thus aids with absorption. HIV/ AIDS infected individuals are susceptible to candidiasis due to the overgrowth of Candida occurring more commonly in immunosupressed individuals. Acidophilus reduces Candida overgrowth. Acidophilus should be administered in a high potency dose three times daily.

Protein powders supply the amino acids required by the body for body tissue repair. HIV/AIDS infected individuals tend to be wasted and thus will benefit from a protein powder. Vitamin B6 $(50 \mathrm{mg})$ and vitamin C (100mg) can be added to the drink so as to ensure better absorption. Where protein drinks are not appropriate due to financial constraints, protein complementation is suggested. 
Colloidal silver is a broad spectrum antiseptic. It can be consumed orally or applied to skin lesions. It is particularly useful for the management of gastrointestinal infection, urinary tract infections and respiratory tract infections.

\section{Herbal medicine}

HIV/AIDS patients generally have high expectations of herbal medicines. "They hold the belief that herbal medicine will slow the progression of the disease, improve the immune system, reduce antiviral toxicity and even provide a cure" (Piscitelli, 2000). Further research into these claims is required.

The following are the most popular herbs available for management of HIV/AIDS: Aloe Vera, Echinacea, elderberry, garlic, ginseng, ginkgo biloba, Goldenseal, Kava Kava, Milk Thistle, St Johns Wort, tea tree and Valerian (Piscitelli, 2000).

Echinacea is the best known and most popularly used for immune function. Echinacea has been found through in vitro and in vivo experimentation to stimulate non-specific cellular immunity. Several constituents of Echinacea are immunologically active. These include polysaccharides, glycoproteins, caffeic acid derivatives and alkamides. The poll-purified polysaccharides derived from Echinacea have been shown to stimulate phagocytosis in vivo and in vitro experimentation. Intravenous administration of the polysaccharides derived from cell cultures of Echinacea activates phagocytes in humans (Grimm \& Muller, 1999:138; Wilson et al. 2002:430).

Echinacea is used for the prevention and treatment of common infectious diseases; including infections of the upper and lower respiratory tract and influensa. Reuss (1996) (in Grimm \& Muller, 1999:138) indicated Echinacea for the use in chronic illnesses such as arthritis and for the use in cancer patients. Echinacea is a potentially useful agent for Candida Albicans and Listeria monocytogenes, chronic fatigue, a variety of skin diseases, wounds and ulcers and chronic pelvic infections. Echinacea is also used for tonsillitis, toothaches, bowel pain, snakebites, rabies, seizures and septic conditions (Grimm \& Muller, 1999:138; Wilson et al. 2002:430).
Although herbs are effective, they are not without side effects. It is also important to note that herbs may reduce the efficacy of certain antiretrovirals. These herbs include Echinacea and St John's Wort (Piscitelli, 2000).

Herbs form the basis of many Chinese medicines. A discussion on Chinese medicine and homoeopathy follows.

\section{Chinese medicine and homoeopathy}

Chinese medicine and homoeopathy are ancient systems of healing and can be very useful in the management of HIV/AIDS. Chinese practitioners use acupuncture and herbs and homoeopaths use energetic medicine. The focus of the healing is on restoring balance to the being, and thus alleviating some of the symptoms associated with HIV/AIDS infection. Practitioners maintain that the disease process is unique to each individual; therefore diagnosis and treatment are highly individualised.

Illness in the context of Chinese medicine and homoeopathy is a disturbance of the vital force. A disturbance in the vital force results in physical, mental and emotional symptoms that is unique to each individual. The inclusion of all the physical, mental and emotional symptoms related to the disturbance in the vital force is known as the totality of symptoms. The totality of symptoms furnishes the truest picture of the health and well-being of the patient and of the particular condition for which treatment is sought. All the symptoms are taken into account and a specific individualised Chinese medicine or homoeopathic prescription that addresses the holistic needs of the HIV/AIDS infected individual is prescribed.

Chinese medicine has many similarities to traditional medicine as they are both ancient forms of healing and take socio-cultural aspects of the patient into consideration.

\section{SOCIO-CULTURAL WELL-BEING}

The socio-cultural well-being of the HIV/AIDS infected individual can be addressed through the use of traditional medicine and lifestyle changes. 


\section{Traditional medicine}

The Health Care System in South Africa has arisen from two origins namely Western Medicine and Traditional Tribal Medicine. This has resulted in two health systems that run alongside each other. Western Medicine is the dominant health system in South Africa. Traditional medicine is defined by the World Health Organisation as: "Comprising therapeutic practices that have been in existence, often for hundreds of years, before the development and spread of modern scientific medicine and still with us today. These practices vary widely, in keeping with the social and cultural heritage of the country" (Dennel, King \& Swanepoel, 1999:183).

Some traditional herbs are being researched for the use in HIV/AIDS management. These include Sutherlandia frutescens as an immunomodulator (Morris, 2001) and Siphonochilus for treatment of candidiasis.

Traditional medicines are useful in the management of HIV/AIDS because a large proportion of the South African population relies on traditional healers. In the light that traditional medicine is in accordance with the traditions and beliefs of the South African population, the incorporation of traditional medicine into community health will allow the local community to support community health program endeavours. Traditional healers are often a first point of contact with HIV/AIDS infected individuals and thus perform a major role in the prevention and treatment of HIV.

The traditional healer has a vital role to play in implementing the lifestyle changes that are necessary following an HIV positive diagnosis.

\section{Lifestyle changes}

Alternative medicine maintains a humanistic view of the HIV/AIDS infected individual. Nursing can also take this humanistic view of the patient through applying the following principles: encouragement through proactive health seeking behaviour, empowerment through knowledge and self-responsibility for health.

Proactive health behaviour is encouraged within alternative health care and involves the choice of a healthy lifestyle. Lifestyle involves the values, beliefs and needs of the total person and thus a person's unique way of living. Changes towards a healthy lifestyle involve behavioural changes, which are not easy as these changes are confounded by many factors. Lifestyle changes involve taking responsibility for preventative health, nutrition, exercise, rest and sleep and stress reduction and stress management programs.

Empowered individuals can make proactive choices about healthy lifestyles and have the ability to view the world, their emotions and their health in a positive light. HIV/AIDS infected individuals are encouraged to make personal decisions about their treatment regime so that they feel more in control of the disease. Research has demonstrated that a positive view of disease, feelings of empowerment, ability to make personal decisions about one's health and strong support structures result in better quality of life and increased duration of survival (Ress, 2001:75).

\section{SPIRITUAL WELL-BEING}

Spiritual well-being is promoted within alternative health. Spiritual well-being is the manner in which individuals view themselves in relation to others and a Supreme Being. A positive relationship with the self and others, self-esteem, life values and belief systems are encouraged. These pertain particularly to disclosing HIV status, realigning relationships with family members, spouses and children and then finally coping with the dying process. HIV/AIDS infected individuals are encouraged to take a positive view of themselves and the disease. Hope and positive thoughts result in improved health outcomes and health perceptions. Hope improves resilience and ability to manage the disease. Meaning and purpose in life is encouraged. Clients who continue to find meaning in their lives after a positive HIV diagnosis are able to improve their self-image and have the ability to improve coping abilities. This results in a more positive disease outcome (Ozsoy \& Ernst, 1999:629; Ress, 2001:75)

\section{CONCLUSION}

The purpose of applying holistic nursing management for the care of the HIV/AIDS infected individual is to 
encourage a balance between the dynamic interactions between the body, mind and spirit. This may lead to improved quality of life of the HIV/AIDS infected individual and thus improved health outcomes, duration of survival and, ultimately, overall well-being.

The usefulness of alternative therapies has been demonstrated and thus should be placed under the same scrutiny as allopathic therapies. The alternative therapies should be subjected to clinical trails and their safety established. Academic institutions should adopt a more proactive posture concerning academic research. Development of nursing curricula, nursing credentialing and referring guidelines are required so as to improve the quality of alternative medicine service delivery and prevent drug interactions.

\section{REFERENCES}

BALCH, JF \& BALCH, PA 1997: Prescription for nutritional healing; second edition. New York: Avery.

BARTLETT, MD \& GALLANT, JE 2000: 2000 - 2001 Medical management of HIV infection. Baltimore: Johns Hopkins School of Medicine.

DEPARTMENT OF HEALTH 2000. HIV/AIDS/STI strategic plan for South Africa: 2000-2005.

DENNEL, K; KING, L \& SWANEPOEL, T 1999: Aspects of primary health care: community health care in South Africa; second edition. Cape Town: Oxford University Press.

DE VISSER, R \& GRIERSON, J 2002: Use of alternative therapies by people living with HIV/AIDS in Australia. AIDS Care, 14(5):599606.

DOUGLAS, RM; CHALKER, EB \& TREACY, B 2000: Vitamin C for preventing the common cold. Cochrane Database Systems Review. (2): CD000980.

ELION, RA \& COHEN, C 1997: Complementary medicine and HIV infection. Primary Care, 24(4):905-919.

GREENE, KB; BERGER, J; REEVES, C; MOFFAT, A; STANDISH, LJ \& CALABRESE, C 1999: Most frequently used alternative and complementary therapies and activities by participants in the AMCOA study. Journal of Association of Nurses AIDS Care, 10:60-73.

GRIMM, W \& MULLER, HH 1999: A randomised control trail was conducted in order to determine the effect of fluidextract of Echinacea purpurea on the incidence and severity of colds and respiratory tract infections. American Journal of Medicine, 106(2):138-143.

HEINRICH, U; GARTNER, C; WIEBUSCH, M, EICHLER, O; SIES, H; TRONNIER, H \& STAHL, W 2003. Supplementation with beta-carotene or a similar amount of mixed carotinoids protects humans from UV induced erythema. Journal of Nutrition, 133(1):98-102.

HULME, J; WATERMAN, H \& HILLOER, VF 1999: The effect of foot massage on patients' perception of care following laparoscopic sterilization as day care patients. Journal of Advanced Nursing, 30(2):460-468.

KIRKPATRICK, GL 1996: The common cold. Primary Care, 24(4):657-675.

MORRIS, K 2001: Treating HIV in South Africa: a tale of two systems. Lancet, 357(9263):1190.

OZSOY, M \& ERNST, E 1999: How effective are complementary therapies for HIV and AIDS? A systemic review. International Journal of STDs and AIDS, 10:629-635.

PISCITELLI, SC 2000: The use of complementary therapies by patients with HIV: Full sail into uncharted waters. Medscape HIV/ AIDS, 6(3):1-6.

RESS, B 2001. Caring for patients with HIV disease in the new millennium. Critical Care Nurse, 21(1): 69-76.

STANDISH, LJ; GREENE, KB; BAIN, S; REEVES, C; SANDERS, F; WINES, RCM; TURRET, P; KIM, JG \& CALABRESE C 2001: Alternative medicine usage in HIV positive men and women: demographics, utilisation patterns and health status. AIDS Care, 13(2):197-208.

WARDELL, D W \& ENGEBRETSON J 2001. Biological correlates of Reiki healing. Journal of Advanced Nursing, 33(4): 439-445. WILSON, D; NAIDOO, S; BEKKER, L; COTTON, M \& MAARTENS, G 2002: Handbook of HIV Medicine. Cape Town: Oxford. 